\title{
19. Community struggles and the challenges of solidarity in Myanmar
}

Ponpavi Sangsuradej

Myanmar is not unfamiliar with disaster. The country was hit in 2008 by Cyclone Nargis, which led to 90,000 confirmed deaths and US\$ Io billion in damage (Hurricanes: Science and Society 2015). Defying the military government's resistance to local and international aid, self-organised Burmese citizens rallied to support residents of the heavily flooded Irrawaddy Delta (Adams 2009). In 2020, Myanmar's elected government oversaw the country's official response to the COVID-I9 pandemic, but the self-mobilisation of communities remained prominent. While the Myanmar government framed its efforts against the disease as demonstrating and inspiring national solidarity, many of its responses failed to account for the pervasive social and economic divisions within the country. This chapter primarily covers COVID-I9 prevention efforts in Myanmar from the start of the COVID-I9 pandemic until September 2020, with some comment on the military coup that began on I February 202 I and as of April 202I was still ongoing. The chapter explores state and community-based responses, including the Myanmar government's uneven and politicised pandemic relief, challenges of urban civil society efforts in informal settlements, and community-level initiatives in rural areas. I argue that community-level responses to the COVID-I9 pandemic further highlighted Myanmar's existing socio-economic divides and ethnic conflicts.

\section{A divided nation}

After its independence from Britain in 1948, Myanmar was plagued by decades of civil war between ethnic minorities and the Myanmar army (Tatmadaw), which took control of the state in a I962 coup. This authoritarian rule resulted in further ethnic conflict and economic

How to cite this book chapter:

Sangsuradej, Ponpavi. 2022. 'Community struggles and the challenges of solidarity in Myanmar’. In: Shin, Hyun Bang; Mckenzie, Murray; and Oh, Do Young (eds) COVID-I9 in Southeast Asia: Insights for a post-pandemic world. London: LSE Press, pp. 2I8-227. DOI: https://doi.org/I0.3 I389/lsepress.cov.s License: CC BY 4.0. 
mismanagement that continued to hinder the country's progress. Although the country saw its first freely elected government in 2015, poverty remained an important issue for Myanmar. The World Bank reported that, in 20I7, the poor population in rural areas was 6.7 times higher in absolute terms than in urban areas, where economic development was more prevalent (World Bank 20I9). The poorest families lived in the ethnic minority Chin State, suggesting a geographical correlation between poverty and the ongoing ethnic conflicts (World Bank 20I9).

Economic and social development projects have been concentrated in urban areas such as the Mandalay and Yangon regions. Urban poverty, however, has remained a concern. For example, Yangon's informal settlements contained as many as 400,000 people, or $8 \%$ of the region's population (UN-Habitat 2020a, p.5). The socio-economic divides both within urban areas and between urban and rural settlements were evident in various official and community-based responses to the COVID-I9 crisis, thus posing a real challenge to the already-divided nation.

While the general election in November 2020 saw a landslide for the civilian National League for Democracy, Myanmar fell into one of its darkest periods when the military staged a coup on I February $202 \mathrm{I}$ and arrested dissidents, politicians, and citizens alike. To oppose the military takeover, people took to the streets as part of a nationwide civil disobedience movement. More than I03,000 government health workers went on strike and joined the movement (Frontier Myanmar 202Ia). It was undeniable that health workers' strikes hindered the COVID-I9 pandemic response, but a common protest refrain was that 'the military is more dangerous than COVID-I9' (Frontier Myanmar 202 Ib).

\section{State inefficiency amid public health crisis}

Back in March 2020, though Myanmar had only seen five positive COVID-I9 cases, the pandemic caused heightened alarm among citizens. With factories closed and lockdown impending, tens of thousands of Burmese migrants were returning from Thailand and Malaysia. The Myanmar government, however, was not ready to cope with such a large number of returnees. Myanmar citizens were alarmed by inconsistent state quarantine procedures. With migrants confused, many of them resisted quarantine enforcement, crossing the Thailand-Myanmar border undocumented or fleeing from the buses before reaching Yangon's Aung Mingalar bus station to avoid checkpoints and mandatory quarantine 
(Ye Mon, Hein Thar, and Eaint Thet Su 2020). News channels displayed chaotic scenes of migrants trying to catch taxis and mingling in crowds. Inconsistent enforcement of quarantine exacerbated the anxiety. For example, 2,000 returnees were reportedly restricted to a quarantine facility, while the next day many thousands of newcomers were let go without having to go through the same procedure (Ye Mon, Hein Thar, and Eaint Thet Su 2020). Moreover, different rules and measures were introduced in different regions and states. By 23 March 2020, at least 2I 5 out of Myanmar's 54 million people had tested positive, but COVID-I9 testing was only available to those who had symptoms, which worried citizens because of asymptomatic cases (Leong 2020). Questions such as 'who will have to go through state quarantine?', 'why did some get away?', and 'who will get tested?' were whispered. Lack of resources meant insufficient staff and testing kits at border checkpoints (Ye Mon, Hein Thar, and Eaint Thet Su 2020).

The macroeconomic fallout of the COVID-I9 pandemic in Myanmar heavily affected the country's households (ADB 2020). From April to May 2020, the Asia Foundation surveyed 750 businesses, which had reportedly laid off I $6 \%$ of their workforces (Asia Foundation 2020, p.I3). Moreover, the government's new social distancing regulations put a burden on vulnerable members of society. The construction industry was heavily hit by the crisis. The government imposed new restrictions of 50 people per construction site, a significant decrease from I,, 00 workers during pre-COVID-I9 times (Rhoads et al. 2020). This resulted in a huge drop in the employment of day labourers.

One of the main challenges was Myanmar's informal economy. Its large unbanked population became a problem for the government's COVID-I9 fund and Economic Relief Plan (CERP), which was aiming for a resilient recovery through tax relief, credit for businesses, and food and cash for households. The CERP received criticism for its non-inclusiveness and inflexible spending targets (World Bank 2020). Two immediate relief efforts targeted vulnerable families: a special handout of five basic commodities (rice, cooking oil, salt, onions, and beans) in April 2020, and a two-instalment cash payment of 40,000 Myanmar kyat (around £22) in July and August 2020 (Htin Lynn Aung 2020). The eligibility criteria, however, were very narrow: a whole family would be excluded if any member owned land or was registered as having formal employment. In Myanmar's traditional households, several generations live together. Owing to these criteria, the entire family would miss out on the government's cash assistance if even one family member was ineligible (Rhoads 2020). These measures deepened the 
vulnerabilities of those already most affected by the economic impacts of the pandemic.

\section{Self-mobilisation in urban areas and challenges on informal settlements}

There were various reactions to the government's calls for public cooperation in the fight against the pandemic. The Myanmar government's response to the COVID-I9 pandemic was shaped by its long-term aim of national unity. In contrast to ongoing and historical conflicts among the government, the military, and the wider population, the pandemic presented an invisible and external common enemy that threatened the physical body of the nation and its individuals. Mask-wearing in Myanmar was seen not just as a matter of self-protection but as a demonstration of a commitment to protect others. A sense of solidarity also pushed many civil society organisations to initiate community-based responses to facilitate state-led projects, e.g. assisting government staff in food distribution. Other efforts included food donations by local charities, student blood donation drives, and hotel owners providing free stays to healthcare personnel (Rhoads et al. 2020). This solidarity also manifested in initiatives aimed at addressing the perceived gaps in the government's response. In April 2020, the charity group People to People distributed basic goods to 2,660 trishaw drivers across Yangon who had lost their income during lockdown (Eaint Thet $\mathrm{Su}$ 2020). Other charity groups provided assistance, including funeral services and a free $24 / 7$ ambulance service. These types of community efforts were widely publicised on social media. For example, a story of Myanmar citizens donating their electricity subsidy to aid the state's coronavirus fight was widely shared on social media (Kyaw Phyo Tha 2020). However, such solidarity efforts, while popular among urban dwellers who lived in relatively more affluent areas, did not engage with or attempt to address the socio-economic problems that necessitated these campaigns in the first place.

The scale of informal settlements in Yangon posed a challenge to tackling transmission. As reported in $2020,400,000$ people or $8 \%$ of Yangon's population lived in 423 informal settlements across the city (UN-Habitat Myanmar 2020a, p.5; see Figure I9.I). These communities had been living under threat of eviction since 20I8. Moreover, as more than $70 \%$ of informal settlers were not registered on any housing record, the pandemic was a threat to their livelihood, income, and tenure. Relief efforts by the state and NGOs were hindered by a lack of 
Figure 19.1. Map of informal settlements in Yangon

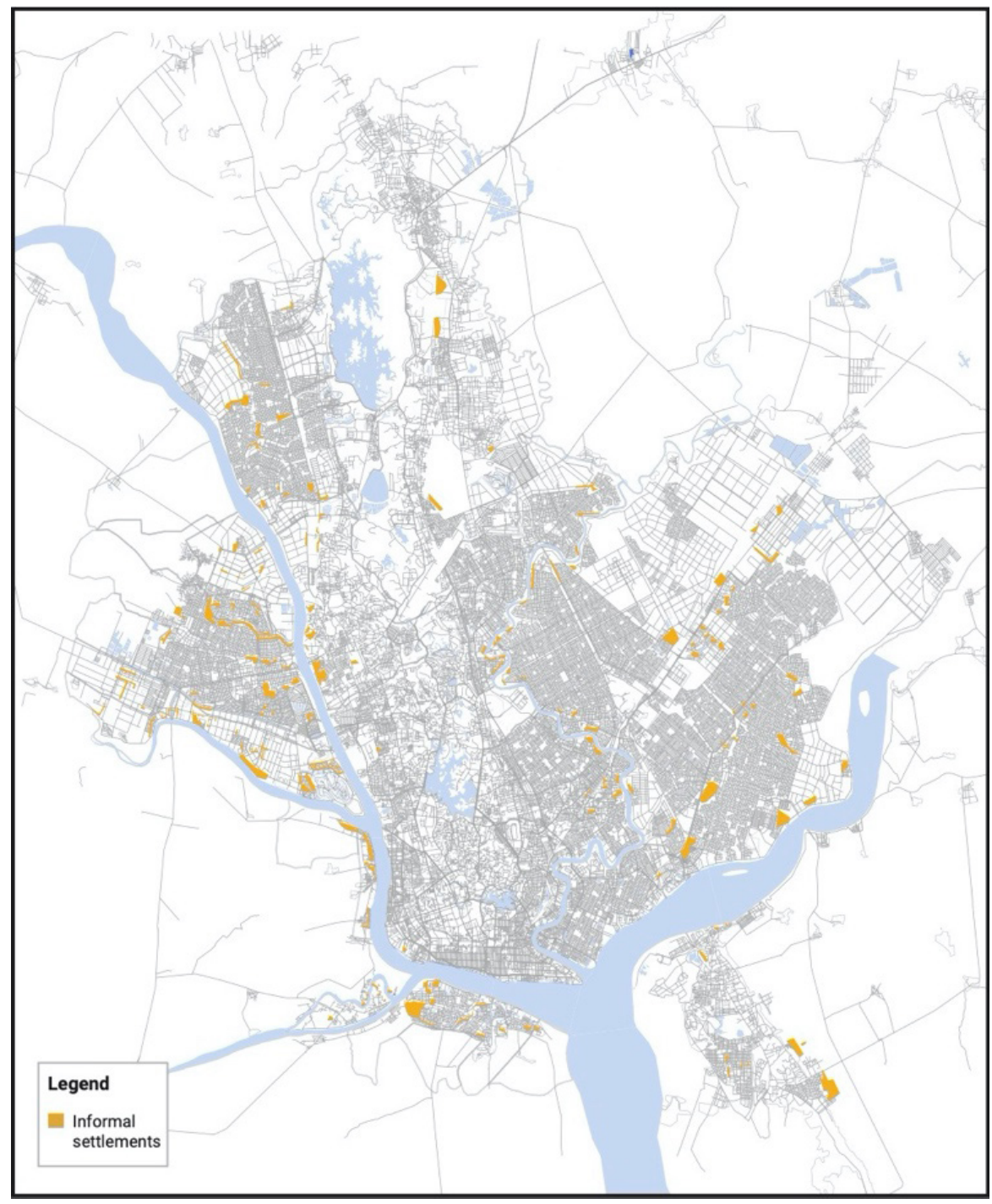

Source: UN-HABITAT Myanmar (2020a).

Note: Informal settlement areas are shown shaded orange.

data on the ground (UN-Habitat Myanmar 2020b, p.6). Moreover, according to a survey of the impact of the pandemic on informal settlements, $8 \mathrm{I} \%$ of the surveyed households had at least one member who had lost their job in the preceding 30 days and $94 \%$ reported a decrease in household income (UN-Habitat Myanmar 2020b, p.I2). In addition to lost income, the lockdown hindered communal projects that would have been of help during these times. For example, residents of urban 
savings groups used to meet daily before the pandemic to deposit savings, which enabled them to save a small amount for recurring costs such as electricity, rent, and food. Some groups even collected savings for community development projects such as sewage works (Rhoads et al. 2020). The ban on assembly, however, prevented regular community gatherings that used to bring together Io or 20 people (Rhoads 2020).

Civil society actions were key to the prevention of COVID-I9 in more disadvantaged areas, especially informal settlements. Community efforts in informal settlements underlined the existing inadequacy of government functions in the community. Local civil society organisations and self-organised parahita (voluntary sector) groups used their local knowledge and contacts to act as leading responders. The parahita groups provided training and tools to prevent the spread of coronavirus (Rhoads et al. 2020). They also coordinated with local and state governments to distribute food to those who did not meet the criteria for state aid. They distributed water and masks, sprayed disinfectants, and organised waste collection (Rhoads et al. 2020). According to UNHabitat's survey (2020, p.4), half of the surveyed households feared eviction. As many residents lost their jobs in the informal sector, they decided to take loans for day-to-day expenses.

With an imminent fear of eviction by the government, several informal settlers' groups attempted to prove their worth as 'good citizens' and contribute to national solidarity. The Bawa Pann Daing business group from the informal settlement of Dagon Seikkan township started making masks in response to a shortage thereof (Liu 2020). Comprising I 5 women, the self-sufficient venture produced 6,000 hand-sewn cotton masks. The group donated around 5,000 to the community and 800 to the local government. Often seen as society's outcasts, the group's members hoped that their contribution would alleviate the threat of eviction (Liu 2020).

\section{Experiences in rural areas}

In contrast to the campaigns by civil society in urban areas, community actions in rural areas were often driven by distrust towards a government that community members felt was neglecting them. The inconsistent quarantine measures mentioned earlier confused not only domestic travellers but also locals. Different states and regions introduced varying rules: quarantine ranged from zero to $2 \mathrm{I}$ days in state facilities. Some even required a health certificate for travellers (Ye Mon 2020). Lacking or distrusting official guidance, many villages organised their 
own informal checkpoints and mandated quarantine procedures to prevent the spread of COVID-I9 and ensure their safety. West of the Yangon region, the Phya Tha Dike village tract ${ }^{\mathrm{I}}$ administrator and village elders decided among themselves to set up a school as a quarantine facility - similar measures were adopted in many areas across the country. The villagers felt it was a crucial step, as people in rural areas were already struggling to access healthcare services (Kyaw Ye Lynn, Ye Mon, and Naw Betty Han 2020). The Phya Tha Dike village had only one qualified healthcare worker, a midwife, and not enough tools and staff if an outbreak were to occur (Kyaw Ye Lynn, Ye Mon, and Naw Betty Han 2020).

Antagonistic feelings rose, especially towards migrants seen as bringing a disease from abroad (Lotha 2020). Many returnees from big cities like Yangon also faced stigmatisation and were forced to quarantine in community facilities far from their villages despite an order from the government that allowed domestic travellers to quarantine in a private home (Pollock and Aung Thet Paing 2020, p.2). Attitudes such as 'we don't know who's infected and who's not' caused fear and rifts in the community, as rumours were spread of returnees ignoring quarantine altogether (Lawi Weng 2020). It was hard to check who followed home quarantine in Burmese households, as private rooms were not always available (Pollock and Aung Thet Paing 2020, p.2).

Even though the villages took inspiration from state quarantine guidelines, there was no guarantee of a consistent standard. In Mon State, more than 36 township facilities operated largely on community initiatives (Kyaw Ye Lynn, Ye Mon, and Naw Betty Han 2020). Some smaller Mon townships, however, later shut down their own community-level quarantine centres and relegated returnees to a more centralised facility in town (Lawi Weng 2020). Throughout this continuous confusion, the state government was not involved (Lawi Weng 2020). These local facilities were initiated by local civil society organisations that donated money for medical supplies and human resources to carry out the project. For example, a volunteer group formed in February 2020 ran a community quarantine facility in Mon State's Ye township at their own initiative (Kyaw Ye Lynn, Ye Mon, and Naw Betty Han 2020). In April 2020 , the government ordered that all quarantine schemes organised by wards and villages would need the approval of the regional committee, but this was met with resistance from locals (Kyaw Ye Lynn, Ye Mon, and Naw Betty Han 2020). Although local practices might not have followed government rules, many communities preferred breaking the law to sacrificing their own safety. 


\section{Conclusion}

Community responses to the COVID-I9 pandemic in Myanmar highlighted existing social and economic divides that had long been mishandled by the government. Positive responses seemed to come mainly from relatively affluent urban dwellers, while marginalised informal settlements, densely populated with low hygiene standards and scattered throughout the city, persisted. Dealing with the COVID-I9 pandemic should have been an opportunity for the state to realign its view of these communities as being part of society rather than forgotten outcasts.

Community reactions to the central policies of regional and ward quarantine reflected wider political, economic, and ethnic divides and mistrust between the central government and the states. In 2020 , Myanmar's governments continued their crackdown on critics, just as was done after 2008's Cyclone Nargis (Adams 2009). Even the democratically elected NLD government attempted to assert broad control over local organisations and threatened the livelihoods of many, especially ethnic minorities across the country. For example, anti-government statements were banned in Kayah State (Zue Zue 2020). Aung San Suu Kyi's aspirations of national solidarity were an illusion for many, as the government continued its oppression, attempting both to eradicate the disease and to stifle criticism of its response.

During the first months of the pandemic, Burmese citizens' reactions to state pandemic policies indicated wider political fractures and mistrust towards the authorities. The violent military coup of February $202 \mathrm{I}$ then obliterated any chance to mend these divides. As of April 202I, nationwide protests and mass civil disobedience were continuing, and over 750 civilian deaths had been reported (Reuters 202I). The military's brutal actions utterly severed any link between communities and the state, leaving the fate of the entire nation uncertain.

\section{Note}

I. A village tract is the lowest subdivision of the Myanmar government administrative structure.

\section{References}

Adams, Brad. (2009). 'The lessons of Cyclone Nargis'. Human Rights Watch, 3 May. https://perma.cc/8ZW3-8EF2 [Last accessed 2I August 2020].

Asia Foundation. (2020). COVID- I9 Impact on Businesses: A Survey, 5 June. https://perma.cc/8283-ZT7R [Last accessed ro August 2020]. 
ADB (Asian Development Bank). (2020). Economic Indicators for Myanmar, September 2020. https://perma.cc/QN9P-AYQ7 [Last accessed 3 February $202 \mathrm{I}]$.

Eaint Thet Su. (2020). 'Charities, civil society lend a helping hand to the needy'. Frontier Myanmar, I6 April. https://perma.cc/9UE2-79TE [Last accessed I 5 August 2020].

Frontier Myanmar. (2021a). "More dangerous than COVID-I9": Antimilitary fury leaves SAC pandemic response in shambles', 25 March. https:// perma.cc/V9KB-PGYG [Last accessed 29 April 202I].

Frontier Myanmar. (202Ib). 'Striking health staff boycott COVID-I9 jabs as the CDM grows', 9 March. https://perma.cc/JZD 5-R226 [Last accessed 29 April 202I].

Htin Lynn Aung. (2020). 'Millions of families get first COVID-I9 relief payments'. Frontier Myanmar, I August. https://perma.cc/A47M-Z 4 GD [Last accessed I 5 August 2020].

Hurricanes: Science and Society. (20I 5). Cyclone Nargis. https://perma.cc/L4 WK-T6YL [Last accessed 2I August 2020].

Kyaw Phyo Tha. (2020). 'Myanmar citizens give up power subsidy to aid COVID-I9 fight'. The Irrawaddy, 8 April. https://perma.cc/3 $\mathrm{N}_{5} \mathrm{~J}-\mathrm{MMZK}$ [Last accessed 29 April 202I].

Kyaw Ye Lynn; Ye Mon; and Naw Betty Han. (2020). 'Community quarantine: On the rural frontline in the fight against COVID-I9'. Frontier Myanmar, I7 April. https://perma.cc/U5AF-PHMT [Last accessed I 5 August 2020].

Lawi Weng. (2020). 'Myanmar's Mon State consolidates quarantine centers for returning migrants'. The Irrawaddy, 6 April. https://perma.cc/4SNR $-{ }_{5} \mathrm{~N}_{5} \mathrm{R}$ [Last accessed 29 April 202I].

Leong, Wai Kit. (2020). 'Enough COVID-I9 test kits for Myanmar, says WHO representative'. CNA, 24 March. https://perma.cc/XK95-L9T6 [Last accessed 29 April 202I].

Lotha, Lesly. (2020). In Myanmar, quarantine facilities become first responders for returning migrant women. UN Women, I7 September. https://perma .cc/2ZL2-JLYY [Last accessed 29 April 202I].

Liu, John. (2020). 'Yangon's informal settlers stitching together a new community’. Myanmar Times, 26 June. https://perma.cc/GZJ2-GFSU [Last accessed I 6 August 2020].

Nwet Kay Khin. (2020). 'Hitting where it hurts: Impacts of COVID-I9 measures on Myanmar poor'. Transnational Institute, 6 July. https://perma.cc /CDC 7 -HEY 2 [Last accessed 3 February 202I]. 
Pollock, Jacqueline; and Aung Thet Paing. (2020). 'COVID-I9: Impact on migrant workers and country response in Myanmar'. International Labour Organization, 20 June. https://perma.cc/R745-WTSS [Last accessed 29 April 202I].

Reuters. (202I). 'Fighting erupts in Myanmar; junta to "consider" ASEAN plan', 27 April. https://perma.cc/XBF3-LRDB [Last accessed 29 April 202I].

Rhoads, Elizabeth. (2020). 'COVID-I9 pandemic and Myanmar's response'. The London Burma Reading Group. Unpublished transcript.

Rhoads, Elizabeth; Thang Sorn Poine; Cho Cho Win; and Kyed, Helene. (2020). Myanmar Urban Housing Diagnostic and COVID-I9 Rapid Assessment. USA: World Bank. https://perma.cc/ZG77-YB97 [Last accessed 4 August 2020].

UN-Habitat. (2020a). COVID-I9 Discussion Paper on Policy Options for Myanmar. Myanmar: UN-Habitat. https://perma.cc/K396-LZX 7 [Last accessed 29 April 202I].

UN-Habitat. (2020b). Rapid Assessment of Informal Settlements in Yangon: COVID-I9 pandemic and its impact on residents of informal settlements. Myanmar: UN-Habitat. https://perma.cc/RC2Q-MTGR [Last accessed Io August 2020].

World Bank. (2019). Poverty Report - Myanmar Living Conditions Survey 20I7, 26 June. https://perma.cc/F63 F-63SM [Last accessed 29 April 202I].

World Bank. (2020 ). Myanmar's Economy Severely Impacted by COVID-I9: Report, 25 June. https://perma.cc/ ${ }_{5} \mathrm{MM}_{5}-\mathrm{K}_{7} \mathrm{BD}[$ Last accessed I9 August 2020].

Ye Mon. (2020). 'Inconsistent quarantine rules leave domestic travel uncertain'. Frontier Myanmar, 3 June. https://perma.cc/AZ35-JCAM [Last accessed I 5 August 2020].

Ye Mon; Hein Thar; and Eaint Thet Su. (2020). 'Alarm as thousands of returning workers ignore quarantine orders'. Frontier Myanmar, 27 March. https://perma.cc/BQ45-8DJB [Last accessed I 5 August 2020].

Zue Zue. (2020). 'Myanmar's Kayah State angers activists with protest ban'. The Irrawaddy, 7 May. https://perma.cc/KU77-JJRM [Last accessed 20 August 2020]. 